\title{
OR-13
}

\section{Resveratrol Trimer Derivative with C7-C14 type of Condensation, an Uncommon Oligostilbenoid type from Dryobalanops Aromatica}

\author{
N. Ahmat*, A. Wibowo and A. S. Hamzah \\ Faculty of Applied Sciences, Universiti Teknologi MARA, 40450 Shah Alam, Selangor Darul Ehsan, Malaysia; \\ E-mail: noriz118@salam.uitm.edu.my
}

The uniqueness and complexity structure of oligostilbenoids in each family or genera has attracted interests from scientists of various disciplines. Based on their carbon-carbon bonding formation, several keys radical species are responsible for the formation of several types of skeleton in the oligostilbenoid. In the Dipterocarpaceae family, the common radical species are resveratrol and $\varepsilon$-viniferin radicals with active sites at carbons $\mathrm{C}_{8}$ or $\mathrm{C}_{14}$, while in other families such as Vitaceae, Cyperaceae, and Gnetaceae the active sites at carbons $\mathrm{C}_{3}, \mathrm{C}_{12}$ or at oxygen atom. In this study, the isolation and purification of acetone extract of the stem bark of Dryobalanops aromatica gave an oligostilbenoid trimer derivative malaysianol A (1) [1] with uncommon condensation type in Dipterocarpaceae family, together with eight common oligostilbenoid types $\varepsilon$-viniferin (2) [2], ampelopsin E (3) [3], diptoindonesin A (4) [4], laevifonol (5) [5], $\alpha$-viniferin (6) [6], flexuosol A (7) [7], vaticanol B (8) and C (9) [8]. Their structures were established on the basis of their spectroscopic evidences and comparison with published data. The biogenetic route of resveratrol trimer involves oxidative coupling reaction between radicals dimer of $\varepsilon$-viniferin (2) and resveratrol [9]. Usually, the dihydrobenzofuran ring in the oligostilbenoid derivatives are formed via oxidative coupling of radical species at $\mathrm{C}_{14}$ with that at $\mathrm{C}_{8}\left(\mathbf{C}_{14}-\mathbf{C}_{\mathbf{8}}\right.$ type). However, the biogenetic route of $\mathbf{1}$ is formed from the oxidative coupling reaction of oxygen ${ }^{\circ} \mathrm{O}-\mathrm{C}_{13 \mathrm{~b}}$ at radical $\mathbf{a}$ and carbon $\mathrm{C}_{8 \mathrm{c}}$ at radical $\mathbf{c}$, followed by the formation of dihyrobenzofuran ring via intermolecular cyclization reaction of $\mathrm{C}_{14 \mathrm{~b}}$ and $\mathrm{C}_{7 \mathrm{c}}\left(\mathbf{C}_{\mathbf{1 4}}-\mathbf{C}_{7}\right.$ type) in the intermediate $\mathbf{e}$ (see Fig. 1, route $\mathbf{i}$ ).

Keywords: Dipterocarpaceae, Dryobalanops aromatica, resveratrol oligomers, malaysianol A and cytotoxic.

\section{REFERENCES}

[1] Wibowo A, Ahmat, N, Hamzah AS, et al. Malaysianol A, a new trimer resveratrol oligomer from the stem bark of Dryobalanops aromatica. Fitoterapia 2011; 82: 676-81.

[2] Oshima, et al., Tetrahedron. Novel oligostilbenes from Vitis coignetiae. 51 (1995) 11979-86.

[3] Oshima and Ueno, Phytochemistry. 33 (1993) 179-82.

[4] Aminah NS, Achmad SA, Aimi N, et al. Diptoindonesin A, a new C-glucoside of epsilon-viniferin from Shorea seminis (Dipterocarpaceae). Fitoterapia 2002; 73: 501-7.

[5] Hirano Y, Kondo R, Sakai K. Novel stilbenoids isolated from the heartwood of Shorea laeviforia. J. Wood Sci. 49 (2003) 53-8.

[6] Pryce RJ, Langcake, P. $\alpha$-Viniferin: An antifungal resveratrol trimer from grapevines. Phytochemistry. 16 (1977) $1452-4$.

[7] Li WW, Li BG, Chen YZ. Flexuosol A, a new tetrastilbene from Vitis flexuosa. J. Nat. Prod. 61 (1998) 646-7.

[8] Tanaka T, Ito T, Nakaya K, Iinuma M, Riswan S. Oligostilbenoids in stem bark of Vatica rassak. Phytochem 2000; 54: 63-9.

[9] Ito T, Ali Z, Furusawa M, et al. Two novel trimeric resveratrol derivatives from Cotylelobium lanceolatum. Chem Biodivers 2005; 2 : $1200-16$ 